\title{
SUBJETIVIDADES
}

Dossiê:

Adolescencia em Psicanálise

\section{DESPERTAR PARA A ALTERIDADE DO CORPO NAS MUTAÇÕES DA ADOLESCÊNCIA}

\author{
Awakening for the Body's Alterity in the Mutations of Adolescence \\ Despertar a la Alteridad del Cuerpo en las Mutaciones de la Adolescencia \\ S'éveiller à l'Altérité du Corps dans les Mutations de l'Adolescence
}

DOI: $10.5020 / 23590777 . r s . v 17 i 3.5764$

Fernanda Guimarães Pougy (OrcID)

Psicóloga, mestre em Teoria Psicanalítica pela UFRJ e doutoranda do Programa de Pós-graduação em Teoria Psicanalítica da UFRJ.

\author{
Angélica Bastos Grimberg (Lattes) \\ Atualmente é Professor Associado II na Universidade Federal do Rio de Janeiro, no Programa de Pós-Graduação em Teoria Psicanalítica e na Graduação. \\ Bolsista de produtividade em Pesquisa do CNPq.
}

\begin{abstract}
Resumo
O presente trabalho aborda a especificidade do período da adolescência para um sujeito, a fim de situar balizas para a compreensão psicanalítica desse tempo, que impõe mudanças corporais e enigmas. Esse novo tempo na relação do sujeito com o Outro nos indica que o corpo constitui sempre uma alteridade problemática, que carece de investigação e discussão, por possuir implicações teórico-clínicas. Situaremos, epistemologicamente, o discurso psicanalítico a partir do advento do sujeito na fundação da ciência moderna com o cogito cartesiano, demarcando as diferentes abordagens dadas pela psicanálise e pela ciência. A exclusão do corpo em direção à extensão e seu retorno no real da clínica serão examinados. A partir do ato freudiano, que recoloca a questão da ligação entre corpo e pensamento, vamos discutir os conceitos fundamentais de pulsão e inconsciente, sublinhando os passos dados por Lacan com a elaboração do conceito de objeto $a$, que culminaram em uma concepção de corpo enquanto substância gozante, ao invés da substância extensa que a filosofia distinguia da substância pensante. Pretendemos abordar as consequências de conferir ao corpo tal estatuto, discutindo a relação do adolescente com a satisfação e a alteridade do corpo.
\end{abstract}

Palavras-chave: adolescência; alteridade; corpo; psicanálise.

\section{Abstract}

This paper discusses the specificity of the period of adolescence for a subject in order to situate references for a psychoanalytic understanding of this period that encompasses body changes and enigmas. This new period in the relationship of the subject with the Other has indicated that the body is always made up of an alterity which is problematic and that lacks investigation and discussion due to theoretical and clinical implications. We will situate epistemically the psychoanalytic discourse from the advent of the subject in the founding of modern science with the Cartesian cogito, demarcating its different approaches according to psychoanalysis and science. The exclusion of the body towards the extension and its return to the real of the clinic will be examined. From the Freudian Act that replaces the issue of the connection between body and mind, we will discuss the fundamental concepts of drive and unconscious, highlighting the steps taken by Lacan in the format of the concept of object a, which culminated in a design of the body as a jouissance substance, instead of the extensive substance that philosophy distinguished from the thinking substance. We intend to address the consequences of giving the body such statute, discussing the relationship of the adolescent with the satisfaction and the alterity of the body.

Keywords: adolescence; alterity; body; psychoanalysis. 


\section{Resumen}

El presente trabajo aborda la especificidad del periodo de la adolescencia para un sujeto, con el fin de situar balizas para la comprensión psicoanalítica de este tiempo que impone cambios corporales y enigmas. Este nuevo tiempo en la relación del sujeto con el Otro nos indica que el cuerpo constituye siempre una alteridad, problemática que carece de investigación y discusión, por poseer implicaciones teórico-clínicas. Situaremos epistemológicamente el discurso psicoanalítico a partir del advenimiento del sujeto en la fundación de la ciencia moderna con el cogito cartesiano, demarcando los diferentes abordajes del mismo, dados por el psicoanálisis y por la ciencia. La exclusión del cuerpo en dirección a la extensión y su retorno en lo real de la clínica serán examinados. A partir del acto freudiano que recoloca la cuestión de la unión entre cuerpo y pensamiento, vamos a discutir los conceptos fundamentales de pulsión e inconsciente, subrayando los pasos dados por Lacan para la elaboración del concepto de objeto a, que culminó en una concepción del cuerpo como sustancia gozante, en oposición a la sustancia extensa que la filosofía distinguía de la sustancia pensante. Pretendemos abordar las consecuencias de otorgarle al cuerpo tal estatuto, discutiendo la relación del adolescente con la satisfacción y la alteridad del cuerpo.

Palabras-clave: adolescencia; alteridad; cuerpo; psicoanálisis.

\section{Résumé}

Ce travail aborde la spécificité de la période de l'adolescence pour un sujet, afin d'esquisser des termes qui permettent la compréhension psychanalytique de ce moment où apparaissent changements et énigmes. Ce temps nouveau dans la relation du sujet à l'Autre nous révèle que le corps constitue toujours une altérité, une problématique qui manque d'investigation et de discussion, pour posséder des implications théorico-cliniques. Nous situerons épistémologiquement le discours psychanalytique à partir de la venue du sujet dans la fondation de la science moderne avec le cogito cartésien, en délimitant les différents abordages de celui-ci, élaborés par la psychanalyse et par la science. L'exclusion du corps en direction à l'étendue et son retour au réel de la clinique seront examinés. A partir de l'acte freudien qui repose la question du lien entre corps et pensée, nous discuterons les concepts fondamentaux de la pulsion et de l'inconscient, soulignant les pas donnés par Lacan avec l'élaboration du concept de l'objet a, qui ont culminé en une conception du corps en tant que substance jouissante, à l'inverse de la substance étendue que la philosophie distingue de la substance pensante. Nous prétendons aborder les conséquences liées au fait de conférer au corps un tel statut, discutant la relation de l'adolescent avec la satisfaction et l'altérité du corps.

Mots clés: adolescence; altérité; corps; psychanalyse.

A começar pelas mudanças que se impõem ao corpo desde a puberdade, a adolescência é um tempo de transições. É importante sublinhar que não há em Freud, ou em Lacan, uma teoria sobre a adolescência. Há considerações a extrair da importância atribuída à infância na vida sexual, isto é, da constatação segundo a qual, independentemente da idade, o infantil é constitutivo da sexualidade, no sentido de que ela se estruture durante a infância como perverso-polimorfa (Freud, 2006a) e preserve ao longo da vida as marcas eróticas no corpo.

Uma vez que ocorrem, sem sombra de dúvidas, mutações na passagem da infância para a adolescência, suas consequências para a sexualidade interrogam o psicanalista quando se trata de situar a especificidade da adolescência para um sujeito, ou melhor, de situar o sujeito diante das mudanças e enigmas que o inquietam na adolescência. As transformações da puberdade foram estudadas por Freud e apontadas como aquelas que levam a vida sexual infantil a sua configuração definitiva. Como alguns pesquisadores e psicanalistas contemporâneos (Deltombe, 2010; Lacadée, 2007; Rego Barros, 2016; Zucchi, 2016), entendemos que essa observação aponta para o encontro com o real do sexo e que, sob o pano de fundo da vida sexual infantil, um novo tempo na relação do sujeito com a alteridade se abre, a partir da experiência com a inexistência da relação sexual, não mais circunscrita ao casal parental, e da tomada de posição na partilha dos sexos, segundo a qual se baliza o modo de gozo de cada um.

Cabe, então, investigar o que subsiste como continuidade e o que se introduz como ruptura no que Freud (1905) denominou "transformações da puberdade" e nas metamorfoses desse tempo que é o da adolescência.

A sexualidade se constitui a partir da relação com o Outro. Essa concepção tem como consequência, por exemplo, que um sujeito possa, como faz o pequeno Hans (Freud, 2006b), localizar um gozo fora do corpo a partir das mudanças que encontra nele mesmo, evidenciando que o corpo seja sempre uma alteridade.

Na saída da infância, é necessário considerar o corpo do Outro dentre os objetos do desejo (Miller, 2015). É isso que podemos extrair das indicações freudianas sobre as ditas transformações (Freud, 2006a), quando se demarca a passagem de uma pulsão sexual predominantemente autoerótica para um objeto sexual externo. 
A ênfase colocada por Freud no autoerotismo para o período da infância se deve à observação de que a criança descubra primeiro a realidade sexual no próprio corpo, para mais tarde desejar um objeto externo. O passo dado por Lacan (1975) quanto a esse ponto é que o encontro com a própria ereção, por exemplo, não seja absolutamente autoerótico, mas o que há de mais hetero, uma vez que o corpo não é auto e sim alteridade.

Diferentemente de Freud, portanto, Lacan não afirma que a transformação da puberdade esteja na transição do gozo autoerótico para a satisfação copulatória, pois conclui que não se goza do corpo do Outro, mas do corpo próprio ou da fantasia. Há uma pergunta a se fazer, porém, sobre a ilusão de gozar do corpo do Outro, posto que esta não deixa de estar presente e ter consequências para o sujeito. Para situá-la, discutiremos a construção da concepção de corpo como substância gozante e do corpo do Outro que representa o gozo do Outro, inexistente (Lacan, 2008a).

\section{Do Cogito ao Inconsciente}

Se respondermos a pergunta sobre o que seja um corpo dizendo que é, simplesmente, uma articulação entre órgãos, que pode ser lida e esquematizada de forma objetiva, teremos como resultado que um automóvel ou um computador são corpos tanto quanto um corpo humano. Assim, reduziríamos a noção de corpo ao maquinário que a relação entre as partes e suas funções, ao se integrarem, compõem; e adotaríamos uma concepção puramente espacial que, como nos lembra Lacan (2008a), se funda na noção de parte e implica um 'partes extra partes', em que todas são externas umas às outras. A experiência analítica aponta que o corpo do ser falante se distingue de tal concepção. Há algo, pelo fato de sermos falantes, que transforma a concepção de corpo e de órgão. Foi justamente isso que a clínica da histeria, no âmago da qual surgiu o campo psicanalítico, apontou.

Os sintomas de conversão, apresentados na histeria e trabalhados por Freud (2006c), recolocaram a questão da passagem do psíquico para o somático. Trata-se de umarelação enigmática entre duas ordens heterogêneas que ficara, para Descartes, definida como um paralelismo.

Descartes foi o primeiro filósofo a estabelecer consequências epistêmicas do corte entre a idade clássica e a modernidade (Koyré, 1963). A ideia de corpo-máquina surgiu a partir da manobra cartesiana que localizou o corpo na substância extensa, tendo como atributos simplesmente o comprimento, a largura e a profundidade. Ele chega a tal conclusão após afirmar o ser a partir do pensamento, supostamente sem precisar do corpo, desligando a substância extensa da substância pensante, e deixando a primeira entregue ao mecanicismo.

O descompasso entre o sujeito e seu corpo é agravado pelo movimento discursivo da ciência, que visa, em cada um destes avanços, abordar o corpo pelo viés do maquinário orgânico. O reducionismo não poupa o falante de que a dimensão do gozo retorne no real, uma vez que, se compreendemos que ele inclui uma vertente pulsional, é impossível que uma máquina seja corpo (Lacan, 1967-68). Os conceitos psicanalíticos fundamentais de inconsciente e de pulsão evidenciam essa impossibilidade, prestando-se a abordar os impasses que o corpo traz ao sujeito na transição incontornável da adolescência.

O cogito cartesiano consiste em uma sucessão de rechaços a todo saber prévio, numa transformação da dúvida em método que chegaria a uma verdade última, uma certeza indubitável, encontrando algo de firme e constante para as ciências. Ele esvazia o espírito de todo saber para, em seguida, devolver o estatuto de verdade às ideias claras e distintas, isto é, as que não tivessem nenhum motivo para serem refutadas (Descartes, 2005).

Não é o valor metódico da dúvida, no entanto, que interessa à equiparação feita por Lacan entre o sujeito cartesiano, da ciência moderna, e o da psicanálise. Segundo Lacan (1998), o sujeito com o qual a psicanálise opera é o mesmo sujeito que a ciência moderna funda. O que importa é o valor de destituição subjetiva que a dúvida acarreta, inaugurando o sujeito propriamente dito, em um despojamento de todo saber, um esvaziamento, um descentramento da imagem que o definia como síntese (Freire, 1996). No próprio pensar, coloca-se uma divisão: penso que penso, penso que duvido ou penso que me engano. Há um pensamento sobre o ato de pensar, que estabelece uma destituição subjetiva, colocando em questão a transparência da consciência a si mesma.

O que o cogito faz emergir é o sujeito da ciência moderna enquanto despojado de toda qualidade, ao qual não "convirão as marcas qualitativas da individualidade empírica, seja ela psíquica ou(sic) somática” (Milner, 1996, p. 33). É este o ponto em que Lacan sublinha que o sujeito seja só um para a psicanálise e para a ciência, embora esta última o exclua para poder operar com os significantes puros da matemática e a primeira se proponha a trabalhar com ele a partir da hipótese do inconsciente.

O pensamento sem qualidades, do primeiro tempo do cogito, é necessário, portanto, para fundar o inconsciente freudiano. Já que o pivô dessa descoberta é a existência de pensamentos no sonho, no chiste, nas parapraxias, etc., o pensamento não é, para nós, entendido como um corolário da consciência de si. "Compreendemos então por que Lacan nunca se vale do que podemos chamar de ponta extrema do cogito e que, de todas as maneiras, ele se esforce em suspender a passagem do primeiro tempo para o segundo" (Milner, 1996, p. 34), no qual Descartes passa diretamente para a consciência de si, fazendo uso do juízo para reaver as verdades simples. 
A descoberta freudiana tem um valor subversivo, justamente, por negar a transparência da consciência a si mesma e apontar a existência de uma divisão subjetiva, afirmando que "[Eu] é um outro" (Lacan, 2010, p. 17). A novidade trazida por Freud (2006a) é a de que o eu não é senhor em sua própria casa, mas sujeito disso que seria a essência do psiquismo e que se passa em Outra cena, no inconsciente. Ele recolhe isto nas chamadas formações do inconsciente, notando que, no que se diz, há a mais um dizer, que não é reconhecido como eu, mas se revela na análise como dizendo respeito a pensamentos inconscientes (Lacan, 2010).

A proposição "se existe pensar, existe algum sujeito" é retirada por Lacan de Descartes e estendida a Freud (Milner, 1996, p. 34). Apontar a existência do inconsciente, porém, tem um efeito de ruptura sobre o cogito. Impõe-se a questão: “Será que nesse 'eu penso', eu aí estou?” (Lacan, 1967-68). Seguindo o raciocínio de Lacan: onde mais certamente penso, ao me dar conta disso, eu lá estava. No entanto, “(...) lá onde isso estava, onde não está mais senão lá, porque sei que o pensei, sollIchwerden" (Lacan, 1967-68), o sujeito deve advir.

Há, sem dúvidas, um saber sobre o corpo construído pela ciência. Todavia, uma das dimensões do mesmo permanece excluída da relação epistemo-somática que tal saber constituiu, isto é, a dimensão de gozo, primeiramente evidenciada pelo sintoma histérico. Dizendo de outro modo, por advir do significante, em uma operação que tem como resíduo último o desejo, o sujeito da certeza, para Freud, é um sujeito desejante. Desidero seria o cogito freudiano (Baas \& Zaloszyc, 1996).

O reducionismo organicista, porém, não poupa o falante de que a dimensão do gozo retorne no real; uma vez que, se compreendemos que o corpo inclui uma vertente pulsional, é impossível que este seja máquina (Lacan, 1967-68). É justamente nesse ponto que a discussão sobre a transição da infância para a adolescência pode nos auxiliar a situar o estatuto de substância gozante do corpo e, consequentemente, que ele seja uma alteridade.

Os conceitos psicanalíticos fundamentais de inconsciente e de pulsão evidenciam essa impossibilidade e se prestam a abordar os impasses que o corpo traz ao sujeito na transição incontornável da adolescência. Portanto, o encontro com o real, essa imisção corpo-linguagem, aponta para a dimensão de gozo.

\section{Corpo e Gozo}

A articulação do inconsciente e da pulsão implica a produção de um resto, chamado de objeto $a$ por Lacan (2005). Através do desenvolvimento desse conceito, pode-se situar o lugar do real e do gozo na dialética do sujeito e do Outro, e avançar rumo à introdução da noção de substância gozante.

Dispondo de recursos da linguística de que Freud não dispôs, Lacan propõe que o inconsciente seja estruturado como uma linguagem. O sujeito do inconsciente, do qual a psicanálise trata, seria um efeito do significante, que se define, justamente, por ser aquilo que representa um sujeito para outro significante e nada mais (Lacan, 1992). Ao tratarmos do aparelho psíquico pela noção de significante estamos falando em termos de um registro simbólico. A tripartição, que orienta o ensino de Lacan, implica e conjuga a este outros dois registros: o real e o imaginário. Nessa concepção, portanto, um corpo é imagem, significante e gozo.

Freud (2006d) percebeu que o sintoma histérico se comportava como se a anatomia não existisse ou fosse desconhecida. O que estaria em questão, afinal, seria "a concepção corrente, popular, dos órgãos e do corpo em geral... Portanto, na paralisia histérica, a lesão será uma modificação da concepção, da ideia de braço, por exemplo" (Freud, 2006d). A comparação entre sintomas de etiologia orgânica e histérica aponta assim para a existência de uma experiência corpórea não pautada na anatomia.

Apesar dos progressos científicos e da extensão cada vez mais eficaz de intervenções terapêuticas concernentes ao corpo humano, o efeito que esses avanços teóricos e técnicos - que visam extirpar o sintoma e explicá-lo deterministicamente no âmbito da pura extensão - produzem é uma falha epistemo-somática (Lacan, 2001). Essa falha é produzida pelo saber científico sobre o corpo devido à exclusão da dimensão do gozo. Ela é de estrutura, não podendo o discurso científico, no qual ela é constitutiva, obturá-la.

A falha epistemo-somática surge e aumenta progressivamente como consequência de os produtos engendrados pelo discurso científico se nortearem pela dicotomia entre pensamento e extensão, estabelecida desde o pensamento cartesiano, e operarem na suposta extensão, a despeito do sujeito. Dessa forma, a ciência

... deixa completamente de fora de sua apreensão aquilo de que se trata, não no corpo que ela imagina, mas no corpo verdadeiro em sua natureza. Este corpo não é simplesmente caracterizado pela dimensão da extensão. Um corpo é algo feito para gozar, gozar de si mesmo. (Lacan, 2001, p.11)

O corpo verdadeiro em sua natureza, a que Lacan se refere, é o corpo que se goza. É o palco de intervenções, como tatuagens e piercings, intervenções estéticas e mutilações, muito comumente usada na fase adolescente como formas de pertencer a um grupo e construir uma identidade. A exposição a situações radicais, recorrentes em adolescentes, põe em risco a integridade física e psíquica. O corpo se goza, atravessado pelo significante. Engorda até a obesidade mórbida nos casos de 
compulsão alimentar, e emagrece, excessivamente, na anorexia. Todos esses casos apontam que o corpo do falante não está pautado, simplesmente, por uma necessidade biológica, mas que essas necessidades estão implicadas com aquilo que Lacan (2008a, p. 57) chamou de Outra satisfação, à qual a necessidade pode, inclusive, faltar.

Não se trata, portanto, de um corpo biológico primeiro, no qual o significante viria se encarnar, desnaturalizando-o. Trata-se do corpo que se constitui no próprio atravessamento significante, não havendo um corpo natural a priori. O que Lacan apontou, em relação ao corpo, é exatamente que qualquer noção de natureza vinculada ao corpo humano está perdida e que não podemos rechaçar a dimensão de gozo que se impõe, uma vez que esse corpo se constitui, nos seres falantes, dentro da função do significante. Isto implica não reduzir a adolescência às transformações da puberdade que afetam o corpo e, sobretudo, não adotar uma perspectiva organicista sobre elas, como não incorrer em um determinismo hormonal pronto a tudo explicar, da instabilidade dos afetos à escolha de objetos.

Retomamos uma questão que Lacan (2010), no início de seu ensino, colocou aos analistas: por que pensamos a vida em termos de mecanismo? A tentativa de cientificizar, de colocar uma ordem em determinados fenômenos, dentre os quais, o da vida, segue, segundo ele, sempre pela via do significante e não pela apreensão direta, como pode parecer intuitivamente. Mas há ainda outra questão a se colocar para que não tiremos disso consequências reducionistas: "dado que somos homens, em que somos, efetivamente, parentes da máquina?" (Lacan, 2010, p. 49).

Parece-nos que ele se refere à função simbólica como operante, tanto na máquina quanto no falante, e que isso abra margem a confusões, mas que precisamos atentar para não extrair disso uma equiparação entre homem e máquina. É o que a experiência analítica aponta ao servir-se do significante de outro lugar (Lacan, 2008a). E que lugar seria esse?

A realidade, desde Freud, é a realidade psíquica. A introdução do que ele chamou de outra cena, o inconsciente, é o essencial para essa compreensão porque tal dimensão “(...) está aí para ilustrar a nossos olhos a distinção radical entre o mundo e esse lugar onde as coisas, mesmo que sejam coisas do mundo, vêm a se dizer” (Lacan, 2005, p.42). Assim sendo, para cada um, as coisas do mundo se colocam segundo as leis do significante. Este é um campo de pesquisa que avança, portanto, marcado por um estilo diferente daquele das outras pesquisas científicas.

Os pensamentos inconscientes não são "o que remexemos sem cessar na nossa cabeça, enquanto gente habituada a pensar", nem tampouco "o que se crê quando fazem fenomenologia do pensamento, o pensamento sem imagens, com imagens etc. Não é o que chamamos correntemente, o pensamento, porque aquilo de que se trata o tempo todo é um desejo" (Lacan, 2009a), p. 58). Ele dá ênfase, assim, à dimensão desejante que aparece no discurso, com a introdução do objeto $a$, objeto causa do desejo.

\section{Sujeito Dividido e Objeto a}

O matema do sujeito barrado, \$, expressa a dependência do sujeito ao Outro como lugar do significante, pois não há acesso ao desejo nem sua possível sustentação, referido a um objeto qualquer, a menos que o acoplando ao Outro. Só há sujeito a partir da introdução de um traço, aquilo a que Lacan dá o nome de traço unário: "é isso que introduzimos no real, queira o real ou não" (Lacan, 2005, p. 31). A partir desse aparelho do traço unário, portanto, advém o sujeito que precisa, então, se arranjar com o fato de que entre ele e o real há o significante.

A relação ao $a$ passa sempre pelo Outro. Sendo assim, em tudo que se segue há a presença do Outro (Lacan, 2005), que está aí como inconsciência e concerne ao desejo na medida do que lhe falta. Portanto, para mim, enquanto sujeito, não há outra via para o que me falta como objeto de meu desejo senão o Outro. A operação da divisão do sujeito, que comporta tais conclusões, é esquematizada, no seminário 10, da seguinte maneira (Lacan, 2005, p. 36):

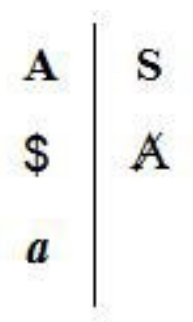

Figura 1. Primeiro esquema da divisão

Fonte: Lacan, J. (2005). O Seminário, livro 10: a angústia (1962-63). Rio de Janeiro: Jorge Zahar Ed., p.36. 
No primeiro nível, encontramos o A, o Outro, como lugar originário do significante, e S, inferência a um momento mítico em que o sujeito não seria barrado. Esse $\mathrm{S}$ é a indicação de que o sujeito é ainda inexistente e precisará situar-se como determinado pelo significante, advindo como \$. Uma vez que o Outro se inscreve na operação como um cociente, o que fica do meu lado (à direita), lado subjetivo do esquema, é aquilo que me constitui como inconsciente, o A, "o Outro como aquele que não atinjo" (Lacan, 2005, p. 36). Enquanto do lado oposto (à esquerda), lado do Outro, há o sujeito, marcado pelo traço unário do significante e dividido por ele, $\$$.

Entretanto, não é por conta do sujeito advir aí, a partir de um traço no Outro, que a operação de divisão seja exata, como se diz em matemática quando o divisor esgota o dividendo sem deixar resto, ou seja, quando os dois termos são comensuráveis. De toda a operação resta ainda um resíduo, o $a$, que Lacan aponta como o Outro derradeiro, garantia da alteridade do Outro e objeto da pulsão, aquilo que falta ao sujeito barrado pelo significante. O objeto resto, portanto, possui coordenadas significantes que o trabalho de análise empreendido pelo sujeito tem por consequência destacar.

Acedendo a uma imagem unificada de si, na fase narcísica, o homem se vê, se concebe, como outro - dimensão estruturante da fantasia, segundo Lacan (2009a). Na constituição do corpo enquanto resultado dessa relação do imaginário, do simbólico e do real, tudo depende de como se situa o sujeito; isto é, de ele se situar simbolicamente, constituindo-se a partir de um lugar no Outro. Nessa constituição, porém, há um resto não especularizável em que inferimos o objeto $a$ (Lacan, 2005), que não é nem um significante, nem pode ser apreendido na imagem, apontando para algo da ordem do real. Isto nos leva à questão do gozo, que também pode ser colocada como a da articulação entre o inconsciente e a pulsão.

Sujeito e objeto, os dois termos da fantasia encontram-se, portanto, do lado do Outro e é por intermédio dela que se responde ao enigma do desejo do Outro e que se goza. Quando o adolescente acede ao parceiro sexual, a fantasia promove a mediação. O próprio da adolescência não é o recurso à fantasia, presente desde a infância, mas seu uso para orientar o encontro com o parceiro e o desejo sexual, embora nem sempre ela esteja em ação nas práticas de gozo. Assim, há casos em que o gozo faz um curto-circuito na relação ao Outro, conforme voltaremos a discutir adiante.

No seminário 11, Lacan (2008b) introduz a pulsão partindo da seguinte definição: "a realidade do inconsciente é a realidade sexual" (Lacan, 2008b, p.148). A sexualidade, deste modo, está referida à nossa relação, ao que se perde, ao objeto, e não à possibilidade de complementaridade. Esta última só seria possível no nível dos seres assexuados, no qual não há perda. Embora a fonte pulsional seja sempre somática (Freud, 2006e), só a conhecemos através de seus representantes. A pulsão seria, nos termos freudianos, um representante dos estímulos oriundos do corpo. Ela estaria representada no psiquismo por uma inscrição, o representante da representação (Vorstellungsrepräsentanz), e pelo afeto (Affekt), que é móbil, ou seja, não permanece, necessariamente, ligado ao representante (Freud, 2006f), instaurando o aspecto dinâmico do aparelho psíquico.

O sujeito é o termo em relação ao qual se situa a satisfação, uma vez que compreendemos o que se apresenta na análise como um esquema onde tudo se arranja e atinge um jeito singular de satisfação (Lacan, 2008b). Em outras palavras, tudo o que um analisando vive e relata ao analista, inclusive seus sintomas, envolve satisfação pulsional. Nesse arranjo de cada um, tanto o que funciona bem quanto o que funciona mal constitui uma série contínua e, por isso, diz-se que o caminho do sujeito passa entre as duas muralhas do impossível (Lacan, 2008b, p.165). Quais são elas? Chamamos a atenção para a indicação de que o oposto do possível é o real (Lacan, 2008b, p.165), como obstáculo ao principio de prazer, aquilo que não se arranja.

Tratar-se-ia do impossível do sexo, incluído nos desfiladeiros do significante. Dito de outro modo, duas faces da moeda: o impossível do sexo e da morte, sobre os quais só podemos falar a partir do significante, mas que não são por ele subsumidos e que vão se impor na adolescência como o que não encontra inscrição; permanece ainda um resto inapreensível. É o de que se trata no que Lacan chamou de inexistência da relação sexual.

A pulsão parcial ser o representante da sexualidade no psiquismo aponta que a sexualidade se instaura no campo do sujeito pela via da falta. O uso da noção de pulsão tem para nós, portanto, o valor de questionar o que é da satisfação, e a fórmula da função do objeto $a$ em sua montagem na busca por ela seria: a pulsão o contorna (Lacan, 2008b). O objeto $a$ tem, assim, a função de causa do desejo. Uma vez que ele falta, é contornando o cavo por ele deixado que o circuito da pulsão demarca as bordas em torno das quais se constrói um corpo.

Embora Freud introduza a pulsão usando os recursos linguísticos, ao destacar em suas vicissitudes as vias ativa, passiva e reflexiva, Lacan (2008b, p.174) observa que isso é apenas um invólucro. O importante é percebermos que a coisa tem dois níveis: um é a reversão significante, e o outro é isso que a veste. Na articulação com o inconsciente, vemos a estrutura de vaivém na qual se monta a pulsão. Além disso, apesar de o verbo designar polaridades, o que se impõe no circuito da pulsão em torno das polaridades não são dois, mas três tempos. Sendo o terceiro a emergência do sujeito.

É preciso bem distinguir a volta em circuito de uma pulsão do que aparece - mas também por não aparecer, - num terceiro tempo. Isto é, o aparecimento de einneues Subjekt que é preciso entender assim - não que ali já houvesse um, a saber, o sujeito da pulsão, mas que é novo ver aparecer um sujeito.

(...) É somente com sua aparição no nível do outro que pode ser realizado o que é da função da pulsão. (Lacan, 2008b, p.175) 
Ao opor o campo do sujeito e do Outro, Lacan assinala uma repartição. O Outro é o lugar do significante, onde se situa tudo que poderá se presentificar do sujeito, do vivo, onde o sujeito tem que aparecer (Lacan, 2008b). É do lado desse vivo que se manifesta a pulsão, sendo sempre parcial - uma vez que nenhuma pulsão representa a totalidade da tendência sexual, devido à ausência de objeto específico que a possa satisfazer, o que leva ao questionamento de um harmonioso encontro com o objeto na adolescência, sob a forma do corpo do Outro. Há sempre um resto na representação sexual do sujeito no Outro. Se há satisfação sem que se atinja o que seria o fim de reprodução, no caso de uma totalização da função biológica, é porque a pulsão é parcial e seu alvo é, justamente, esse retorno em circuito.

O que distingue essa satisfação do puro autoerotismo da zona erógena é o objeto, que só conhecemos enquanto perdido, presença de um cavo ocupável, o $a$. Ele não é a origem da pulsão, mas é introduzido pelo fato de que nenhum alimento jamais satisfará a pulsão oral, por exemplo, a não ser parcialmente, contornando o objeto faltante (Lacan, 2008b, p.177). A satisfação pulsional em torno do objeto não distingue, portanto, o gozo infantil do gozo a que se acede na adolescência, posto que, na infância, o objeto $a$ enquanto falta já se destacou, já há gozo fora do corpo, gozo fálico. Tanto no que Freud chamara de autoerotismo quanto no gozo de um objeto externo, portanto, trata-se de um gozo que envolve o corpo próprio, devido a estrutura de vaivém da pulsão. O que Lacan destacou com isso é que o corpo próprio é, ele mesmo, uma alteridade.

É o que nos mostrou também o caso do pequeno Hans (Freud, 2006b), um menino de cinco anos que desenvolve um quadro fóbico perante o enigma colocado pelo advento de suas ereções. O sintoma foi a saída que a criança deu ao encontro com aquela nova experiência em seu pênis que, a despeito de seu entendimento e vontade, desvelava o estatuto de alteridade do corpo.

O conceito de pulsão seria, assim, tão fundamental quanto o de inconsciente, uma vez que é, logicamente, anterior ao sujeito e, em seu caráter limítrofe, é o elemento que evidencia a ligação elementar entre o corpo e o psíquico. Como vimos, novo é ver surgir, do movimento pulsional, um sujeito, especialmente quando as exigências da ligação com o corpo sofrem incremento na adolescência e as respostas fantasmáticas ao enigma do desejo do Outro não estão à altura das injunções que se apresentam.

\section{As Funções do Objeto}

O objeto $a$ enquanto falta é introduzido como objeto causa do desejo (Lacan, 2008b). Trabalhamos sua localização na estrutura de borda, dando ao campo do sujeito e do Outro sua relação. Também discutimos a lógica subjacente ao objeto, enquanto objeto da pulsão, tendo papel fundamental na constituição do corpo próprio. Mas há ainda sua função como objeto mais-gozar (Lacan, 2008c), que complementa o sentido e a importância desse conceito psicanalítico.

O objeto $a$ havia sido introduzido a partir de sua relação com a angústia, definida enquanto sinal de algo da ordem do real (Lacan, 2005). O $a$ é o que resta na operação do advento do sujeito no lugar do Outro. É justamente aquilo que representa o S em seu real irredutível, \$ (Lacan, 2005, p.179), e é com ele lidamos, segundo Lacan, tanto no desejo quanto na angústia. Ele estabelece três etapas, retomando o esquema da divisão:

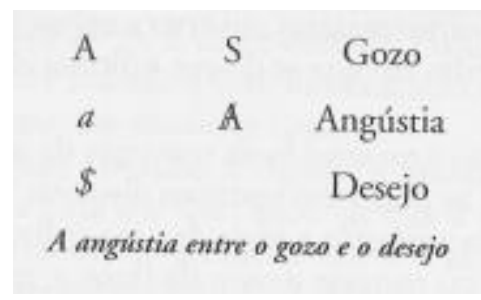

Figura 2. Desenvolvimento do esquema da divisão

Fonte: Lacan, J. (2005). O Seminário, livro 10: a angústia (1962-63). Rio de Janeiro: Jorge Zahar Ed., p.192.

Há, no início, um momento mítico que só podemos inferir retroativamente, anterior ao advento do sujeito como barrado pelo significante e à extração do objeto $a$, momento no qual localizaríamos a plenitude do gozo. Em S, portanto, tratar-seia do sujeito do gozo, caso pudesse existir algo assim, mas "não podemos de modo algum isolá-lo como sujeito, a não ser miticamente" (Lacan, 2005, p.192), pois só há sujeito propriamente dito a partir do significante. Em seguida, haveria o nível da angústia, em que aparece a função do $a$. No terceiro momento, surge o $\$$ como sujeito do desejo.

Dessa maneira, temos que o gozo não conhece o Outro senão através desse resto que é o objeto $a$ (Lacan, 2005); isso quer dizer que o $a$ assumiria a função de metáfora do sujeito do gozo se fosse assimilável a um significante. Mas ele não o é. O $a$ é, justamente, o que se perde para a significantização. 
O mais-gozar é introduzido para designar a incidência do significante sobre o corpo, isto é, uma perda de gozo que incita a sua recuperação. No seminário "De um outro ao Outro", recorrendo a Marx e sua noção de mais-valia, Lacan (2005) isola a função do objeto $a$ como a essência do discurso analítico - aquilo que o distingue de um estruturalismo, campo epistêmico em que alguns o enquadraram, uma vez que Lacan dizia tratar-se em psicanálise de um discurso e destacava a estrutura de linguagem do inconsciente. A esta confusão, ele responde começando por afirmar que a teoria psicanalítica tem por essência a função do discurso, sim. Mas um discurso sem palavras (Lacan, 2008c). O que quer dizer com isso? Ora, o $a$, como vimos, não é um significante, mas aquilo que resiste à significantização.

Lacan diz ainda que, estando agrupado sob o rótulo de estruturalista, não estaria tão mal assim. Mas não seria este o caso, uma vez que o estruturalismo "é a consideração a sério do saber como causa" (Lacan, 2008c, p.14) e, como tudo que foi trabalhado até aqui buscou apontar, o que é específico do campo psicanalítico é guardar o lugar do não-saber, da falta, pois algo do gozo escapa à articulação significante. A causa para a psicanálise é localizada, portanto, na falta e não no saber. O discurso da psicanálise é o único que articula a renúncia ao gozo engendrada pela própria estrutura discursiva, evidenciando a função do mais-gozar.

Lacan (2008c) se detém no mais-gozar fazendo uma homologia entre a função do $a$ e a da mais-valia, em uma referência direta à teoria marxista. Podemos inferir, a posteriori, que desde o esquema da divisão apresentado no seminário 10 - em que, no início, havia um nível pleno de gozo, anterior ao advento do sujeito barrado -, estava indicado que o que daria lugar ao objeto $a$ seria uma renúncia ao gozo, efeito da entrada no discurso.

As diferentes roupagens do objeto $a$ na fantasia, isto é, a relação do sujeito com o objeto $(\$ \& a)$, seriam fabricações em torno das quais poderia produzir-se o mais-gozar. Enquanto na gramática freudiana o corpo oscila entre engolir e ser engolido, ver e ser visto, etc., Lacan enfatiza o caráter sempre ativo da pulsão, mesmo quando esta visa uma posição passiva, falando em termos de fazer-se devorar, fazer-se ver, etc. Assim sendo, compreendemos que "o discurso detém os meios de gozar, na medida em que implica o sujeito" (Lacan, 2008c, p.18) e assim se dá a relação entre o gozo e o significante.

Definindo que um significante representa um sujeito para outro significante, a psicanálise indica que não há um ponto de fechamento do discurso. Diferentemente do pensamento filosófico, que designa uma visão de mundo - Weltanschauung -, no campo psicanalítico a consideração da castração, da falta simbólica, que entra em jogo pela entrada na linguagem, não admite nenhuma harmonia na relação com o Outro. Isto é, um significante não pode representar a si mesmo, uma vez que o sujeito não pode reunir-se em seu representante de significante sem que se produza uma perda, o objeto $a$.

Marx trabalhou sobre o objeto do capital, partindo da análise da função do mercado. Lacan afirma que a investigação psicanalítica permite enunciar algo paralelamente a isto. A novidade trazida pela elaboração marxista é o lugar em que esta situa o trabalho no mercado. O que lhe permite demonstrar a mais-valia é o fato de haver um mercado de trabalho, isto é, que o trabalho possa ser comprado, que a ele se possa atribuir um valor. Em sua teoria sobre o funcionamento do sistema econômico, Marx destacou que os valores atribuídos ao trabalho, vinculados à mercadoria que dele resulta, articulam um valor de uso e um excedente, para sempre perdido para o trabalhador que vendeu sua força de trabalho.

Lacan (2008c) sublinha uma identidade do discurso com suas condições, que é o ponto que lhe interessa esclarecer a partir da homologia traçada entre o pensamento marxista e o psicanalítico. Quando ele relê a mais-valia, atribui esta função, no âmbito da economia psíquica, ao $a$, ou seja, aquilo que se perde para que a rede significante se torne um aparelho de gozo e que engendra o circuito da repetição no qual o sujeito aparece. A economia psíquica que se supõe funcionar nessa estrutura engendra a repetição, pois visa esse gozo que excede, que sobra. Ao mesmo tempo em que a linguagem se coloca como aparelho de gozo, este último mostra, em si mesmo, que está em falta. Ao mesmo tempo em que causa, o significante faz barreira ao gozo. Não há gozo pleno, senão em um momento mítico inferido a posteriori, ou seja, a partir do corte do significante. Algo do lado do gozo sobra, é "desperdiçado" para que isto se dê - para que a linguagem seja seu aparelho.

Assim como em Marx o trabalho não era novidade na produção da mercadoria, a renúncia ao gozo que o discurso psicanalítico procura articular também não é nova. O inédito é a existência de um discurso que o faça e que evidencie nessa renúncia a função de mais-gozar. Função que não se reduz à articulação significante, mas que concerne à falta que esta engendra. Dessa forma, entendemos que se diga tratar-se de um discurso sem palavras. O que importa, para nós, é que em torno do mais-gozar se produz o objeto $a$. "Essa função aparece em decorrência do discurso. Ela demonstra na renúncia ao gozo, um efeito do próprio discurso" (Lacan, 2008c, p.17), um efeito da enunciação.

A fabricação discursiva da renúncia ao gozo que o objeto $a$ designa, portanto, introduz a dimensão do corpo, aquilo que produz uma consistência e a ilusão de ser $e u$. É a partir da extração do objeto, portanto, que um corpo pode fazer aquilo para o que é feito: gozar de si mesmo (Lacan, 1998). O corpo do mais-gozar, apesar de não ser lido pelos aparelhos científicos, sempre está presente no corpo da ciência, equivalendo aí a um saber-a-menos, falha epistemo-somática, e diz-se, por isso, que o corpo retorna do exílio. Mas isso não é lido por tais aparelhos, pois o gozo não é significante, apesar deste último ser, por sua vez, um meio de gozo.

O gozo é perdido de forma inelutável e os objetos que o substituem constituem uma série sem fim: objetos de consumo, objetos tecnológicos, gadgets, objetos das adicções. Com sua dupla vertente, os objetos mais-gozar tanto trazem um 'a-mais' 
quanto contêm um gozo 'a-menos', uma 'falta-de-gozo', tão propícias ao consumo desenfreado e às compulsões suscetíveis de acirramento na adolescência. A recorrência de casos de compulsão na adolescência deve-se à exigência de um incremento do trabalho psíquico para sustentar os encontros e desencontros com o parceiro sexual, que não podem se apoiar nas soluções forjadas durante a infância. A compulsão é uma das saídas, solução sintomática proporcionada pela conjugação entre o discurso da ciência e o discurso capitalista, que pode aparecer de maneira branda ou em formas muito graves e sofridas para o adolescente.

$\mathrm{O}$ efeito de significação depende de que um significante se articule a outro, o que não ocorre sem que haja um resto. Isto, diz Lacan (1992), está na raiz do fato de estrutura e é o que interessa à experiência analítica: que o discurso inclua o impossível, aquilo que escapa à simbolização. "Esse algo que resiste, que não é permeável a todos os sentidos, que é consequência de nosso discurso, a isso se chama fantasia" (Lacan, 2009b, p. 27). A fantasia fornece as balizas dentro das quais a satisfação é possível e certos modos de gozo tornam-se mesmo necessários. Ela é sustentáculo do desejo e esclarece como e por que o objeto com o qual ocorre o encontro no segundo tempo de constituição da sexualidade - que é a puberdade - não é tão externo, o que não quer dizer que seja autoerótico, uma vez que passa pelo Outro.

\section{O Corpo é uma Substância Ggozante}

Constata-se na clínica que algo do sintoma é posto em palavras em consequência de concernir a um corpo pulsional. Descrevendo o inconsciente como uma borda que se abre e fecha, Lacan (2008b) o coloca como estruturalmente homogêneo ao funcionamento da pulsão, imbricando, mais explicitamente, a ordem significante com o real; e indicando que, na experiência analítica, esse exterior inassimilável é "experimentado" pelo sujeito através deste objeto, objeto $a$, que tem "a falta como substância" (Darriba, 2005). Não se trata, portanto, de substância extensa, mas de gozo.

Ter um corpo implica não sê-lo. Não ser um corpo coloca o impasse de ter que lidar com ele em uma extraterritorialidade. O sujeito cria estratégias para isto, as quais aparecem para nós na fala em análise. Acreditamos que a chave para pensarmos o corpo é o que foi recolhido pelo discurso psicanalítico: o gozo, pois para nós, é a substância de que se trata (Lacan, 2008a).

O sujeito surge desde que o significante se encarna (Lacan, 2005). O que permite que isso aconteça é aquilo que temos para estarmos aí um para os outros: nosso corpo. Como vimos, ele não pode ser constituído à maneira de Descartes, puramente no campo da extensão, e também não nos é dado de forma completa pelo reflexo unificado no espelho, pois possui uma parte não especularizável que condensa um gozo. Lacan $(2005$, p.237) opõe o termo objetividade, enquanto termo supremo do pensamento científico ocidental, à objetalidade, "o correlato de um phatos de corte". O objeto perdido nesse corte, libra de carne, constitui o suporte da função da causa, que estabelece a relação ao objeto.

A objetividade, então, estaria referida ao que se encerra totalmente em um formalismo lógico, enquanto a objetalidade seria um derivado do corte. Há formalismo na noção de inconsciente, principalmente quando se destaca seu viés estrutural. Mas o formalismo nos captura por algum lugar, diz Lacan (2005, p.237), pela parte de nós mesmos, parte carnal, que permanece aprisionada na máquina formal, sem a qual o formalismo não seria, para nós, absolutamente nada. Essa parte carnal fica irrecuperável para sempre.

A relação entre o corpo, o significante e o objeto é afirmada a partir do último termo, justamente este que está perdido desde sempre: "essa parte corporal de nós é, essencialmente e por função, parcial. Convém lembrar que ela é corpo e que somos objetais, o que significa que não somos objetos do desejo senão como corpo" (Lacan, 2005, p.237).

Lacan (2008b) falou da suposição de saber para designar o que Freud chamava de inconsciente, isto é, um saber a ser adquirido na análise pelo analisante que, supondo saber inconsciente, colocar-se-ia no trabalho de associação livre e faria suas construções. Mas acrescentou uma segunda suposição, que seria indissociável dela: "a suposição da substância gozante, do corpo suposto gozar" (Miller, 2011, p.186).

O que levou Lacan à segunda suposição, da existência de um corpo suposto gozar, e por que ela é necessariamente articulada à primeira, de um sujeito suposto saber? Ele constatou, pelo fato dos falantes não serem meramente lógicos, - mas afetados, comovidos, trespassados, perturbados pelas palavras - que a função da fala convocava, para além da estrutura da linguagem, o gozo (Miller, 2011).

Para situar o próprio significante no gozar de um corpo - "um corpo que, a Outro, o simboliza" (Lacan, 2008a, p.29) põe-se em função uma forma de substância diferente da substância extensa. Lacan (2008a) nomeia a substância do corpo, na condição de ser aquilo de que se goza, como substância gozante.

A propriedade do corpo vivo, segundo ele, é o gozo e isso só se goza por se corporizar de modo significante. Desde o vitalismo, corrente introduzida no surgimento da biologia, a definição do que seria a vida sempre foi problemática e nunca de fato chegou a se concretizar. Por mais que o campo da biologia exista, produza saberes e opere, as coordenadas do conceito de vida não o ocupam. Embora tenha sido nomeado como o estudo da vida, bio(vida)logia(estudo), nele não se indaga sobre o que ela seja, mas se analisa os sistemas vivos (Jacob, 2001). É, assim, uma biologia sem vida. 
A proposta de Lacan (2008a, p.29) aparentemente define a vida pelo gozo: "não sabemos o que é estar vivo, senão apenas isto, que um corpo, isso se goza". Esta, porém, é mais uma 〈definição do que seja o corpo vivo do que da vida propriamente dita. Ou até mesmo uma definição do gozo, no que a vida é sua condição. Conclui-se, então, que não há gozo sem a vida. Mas não é só isso, como ressalta Miller (2004). Não é simplesmente a afirmação de que não há gozo sem a vida. Trata-se da vida, justamente, sob forma de corpo. "O gozo, ele próprio, é impensável sem o corpo vivo, o corpo vivo que é a condição do gozo" (Miller, 2004, p.8).

Ao mesmo tempo que causa, porém, o significante é aquilo que faz barreira ao gozo, por ser a ele incomensurável. Vimos como essa abordagem do significante foi desenvolvida por Lacan, derivando e servindo ao que é específico do discurso analítico, isto é, "que eu falo sem saber". Até aí, apenas com a suposição do inconsciente, já estava claro. O passo seguinte, que implica o corpo nisto, também não é propriamente novo, poderíamos remeter às histéricas e seus sintomas de conversão. Freud (2006c) mesmo já havia constatado que o corpo estava implicado na estrutura psíquica e trabalhava ali em investigar essa ligação, denunciada pelo sintoma.

Mas Lacan (2008a, p.127) atualiza, em seus termos, a descoberta freudiana e avança no que podemos extrair dela sobre esta ligação: "falo com o meu corpo, e isto, sem saber. Digo, portanto, sempre mais do que sei”. Assim, se chega ao sentido psicanalítico de sujeito: "o que fala sem saber me faz $e u$, sujeito do verbo. Isso não basta para me fazer ser".

Segundo Lacan, o cogito cartesiano comporta um erro sobre o ser, como se pode constatar no exílio do corpo fora do pensamento (Lacan, 1967-68). "Penso, logo sou" significa que ele só pode pensar fazendo-se ser. Rejeita-se que o sujeito só se faz a partir de uma perda, de uma falta, que tem como consequência que ele pense onde não é, onde não se reconhece enquanto $e u$, devido à estrutura da linguagem. Sua constituição na dialética com o campo do Outro impõe que pensemos em termos dos registros real, simbólico e imaginário, o que torna impossível conceber o corpo como pura extensão. Esta seria, como vimos, a foraclusão de Descartes, assinalada por seu efeito que reaparece no Real: o corpo retorna do exílio, confrontando-nos com sua parcela inapreensível pela rede simbólica em fenômenos que apontam a incomensurabilidade do significante e do gozo.

Há como consequência dessa compreensão uma dialética entre dois campos, e um resto que cai entre eles, marcando sua incompletude. Lacan propõe a substância gozante, pois é preciso supor a entidade do corpo para que o gozo tenha um suporte (Miller, 2011, p.187), não bastando o sujeito suposto saber do significante, pura e simplesmente, embora essa substância não seja independente do significante - já que o significante é situado no nível da substância gozante que é o corpo. Assim, passa a poder afirmar, em consonância com o que a clínica apresentava, que "onde isso fala, isso goza" (Lacan, 2008a, p.123).

Sobre essa articulação necessária da substância gozante com o sujeito do significante, Lacan (2008a) esclarece que só se goza do corpo se a substância se corporiza de modo significante. Há um intrincamento do gozo e da fala. O traço unário que funda o aparelho psíquico se constitui como a matriz da incidência do Outro sobre o corpo e o marca como carne para gozar. "Aqui, a marca é também um significante paradoxal: ela não entra num sistema que seria a estrutura da linguagem. Ela vale como uma insígnia, solitária, absoluta, que identifica um corpo como objeto de gozo" (Miller, 2011, p.188).

Tomar o corpo dessa maneira, como o que se goza, não significa, porém, dizer que ele se compraz aos montes, mas que ele se afeta. Tanto no deleite quanto na raiva, o que está em jogo é um gozo (Miller, 2011). Tanto no que se julga ser prazeroso quanto na repetição, ou no sintoma, dos quais se queixam enquanto desprazerosos, há gozo. É de uma Outra satisfação, portanto, o de que se trata. As necessidades do ser falante estão implicadas com a outra satisfação, que nada deve ao registro natural (Lacan, 2008a).

O gozo do qual a satisfação baseada na linguagem depende articula-se ao desejo pelo fato de que o signo de gozo seja o próprio causador do desejo. Ele é, na medida em que falta. “(...) uma vez tirado, o objeto pequeno $a$ que ocupa esse lugar só deixa nele, nesse lugar, o ato sexual tal como eu o acentuo, ou seja, a castração" (Lacan, 2009b, p.71).

\section{Para Concluir}

A expectativa ou o fato do encontro com o parceiro e da satisfação copulatória na puberdade coloca no horizonte do adolescente a inexistência da complementaridade entre os sexos. Na impossibilidade de extrair o gozo da relação com o corpo do Outro sexuado, busca-se extraí-lo dos objetos dos quais a tecno-ciência é pródiga. É próprio da aliança da ciência com o discurso do capitalista que os objetos se dirijam diretamente ao sujeito, num curtocircuito que exclui o Outro. Porém, conforme vimos, ela promete mais-gozar tanto quanto imediatamente instala a falta de gozo, seja pelos objetos que, tão logo são consumidos, se tornam obsoletos ou descartáveis, seja pela insaciedade, pela avidez que cultivam.

É pelos aparelhos do gozo que a realidade é abordada, e não há outro aparelho senão a linguagem, o que não quer dizer, porém, que o gozo é anterior à realidade. Pelo contrário, não há a menor realidade pré-discursiva (Lacan, 2008a). Como vimos, o significante é causa de gozo, não podendo lhe ser, portanto, anterior. O que o discurso do analista tem a propor ao 
adolescente é que venha se haver com as coordenadas significantes de seu mais-gozar, que possa separar-se de imperativos de gozo que fazem curto-circuito do Outro. Dessa maneira, abriria-se a possibilidade de criação de uma saída fantasmática menos sofrida para a falta de proporção entre os sexos, na qual o gozo pudesse condescender ao desejo.

\section{Referências}

Bass, B., \& Zaloszyc, A. (1996). Descartes e os fundamentos da psicanálise. Rio de Janeiro: Editora Revinter.

Darriba, V. (2005). A falta conceituada por Lacan: Da coisa ao objeto. Ágora - Estudos em Teoria Psicanalítica, 8 (1), 63-76.

Deltombe, H. (2010). Les enjeux de l'adolescence. Paris: Michèle Ed.

Descartes, R. (2005). Meditações metafisisicas. São Paulo: Martins Fontes.(Originalmente publicado em 1641).

Freire, A. B. (1996). Descartes e o cogito. In A. B. Freire, F. L. Fernandes \& N. S. Souza (Eds.), A ciência e a verdade: Um comentário (pp. 38-50). Rio de Janeiro: Editora Revinter.

Freud, S. (2006a). Três ensaios sobre a teoria da sexualidade. In J. Strachey (Ed.), Edição Standard Brasileira das Obras Psicológicas Completas de Sigmund Freud (Vol. 7). Rio de Janeiro: Imago. (Originalmente publicado em 1905).

Freud, S. (2006b). Análise de uma fobia em um menino de cinco anos. In J. Strachey (Ed.), Edição Standard Brasileira das Obras Psicológicas Completas de Sigmund Freud (Vol. 10). Rio de Janeiro: Imago. (Originalmente publicado em 1909)

Freud, S. (2006c). Estudos sobre a histeria. In J. Strachey (Ed.), Edição Standard Brasileira das Obras Psicológicas Completas de Sigmund Freud (Vol. 2). Rio de Janeiro: Imago. (Originalmente publicado em 1893)

Freud, S. (2006d). Algumas considerações para um estudo comparativo das paralisias motoras orgânicas e histéricas. In J. Strachey (Ed.), Edição Standard Brasileira das Obras Psicológicas Completas de Sigmund Freud (Vol. 2). Rio de Janeiro: Imago. (Originalmente publicado em 1893)

Freud, S. (2006e). Os instintos e suas vicissitudes. In J. Strachey (Ed.), Edição Standard Brasileira das Obras Psicológicas Completas de Sigmund Freud (Vol. 14). Rio de Janeiro: Imago. (Originalmente publicado em 1915)

Freud, S. (2006f). O inconsciente. In J. Strachey (Ed.), Edição Standard Brasileira das Obras Psicológicas Completas de Sigmund Freud (Vol. 14). Rio de Janeiro: Imago. (Originalmente publicado em 1915)

Jacob, F. (2001). A lógica da vida: Uma história da hereditariedade. Rio de Janeiro: Edições Graal. (Originalmente publicado em 1983)

Koyré, A. (1963). Considerações sobre Descartes. Lisboa: Editorial Presença.

Lacadée, P. (2007). L'Eveil et l'exil. Enseignements psychanalytiques de la plus délicate des transitions: l'adolescence. Nantes: Cécile Defaut Ed.

Lacan, J. (1967-68). O Seminário, livro 15: O ato psicanalítico. Link

Lacan, J. (1975). Conferência de Genebra sobre o sintoma. Link

Lacan, J. (1992). O Seminário, livro 17: O avesso da psicanálise (1969-70). Rio de Janeiro: Jorge Zahar Ed.

Lacan, J. (1998). A ciência e a verdade (1965). In J. Lacan, Escritos (pp. 869-892). Rio de Janeiro: Jorge Zahar Ed.

Lacan, J. (2001). O lugar da psicanálise na medicina (1966). Opção lacaniana, (32), 8-14. 
Lacan, J. (2005). O Seminário, livro 10: A angústia (1962-63). Rio de Janeiro: Jorge Zahar Ed.

Lacan, J. (2008a). O Seminário, livro 20: Mais, ainda (1972-73). Rio de Janeiro: Jorge Zahar Ed.

Lacan, J. (2008b). O Seminário, livro 11: Os quatro conceitos fundamentais da psicanálise (1964). Rio de Janeiro: Jorge Zahar Ed.

Lacan, J. (2008c). O Seminário, livro 16: De um Outro ao outro (1968-69). Rio de Janeiro: Jorge Zahar Ed.

Lacan, J. (2009a). O Seminário, livro 1: Os escritos técnicos de Freud (1953-54). Rio de Janeiro: Jorge Zahar.

Lacan, J. (2009b). O Seminário, livro 18: De um discurso que não fosse semblante (1970-71). Rio de Janeiro: Jorge Zahar Ed.

Lacan, J. (2010). O Seminário, livro 2: O eu na teoria de Freud e na técnica da psicanálise (1954-55). Rio de Janeiro: Jorge Zahar Ed.

Miller, J. A. (2004). Biologia lacaniana e acontecimentos de corpo. Opção lacaniana, (41), 7-67.

Miller, J. A. (2011). Perspectivas dos escritos e outros escritos de Lacan. Rio de Janeiro: Zahar.

Miller, J. A. (2015). Rumo à adolescência. Link

Milner, J.-C. (1996). A obra clara: Lacan, a ciência, a filosofia. Rio de Janeiro: Jorge Zahar Ed.

Rego Barros, M. R. C. (2016). Saída da infância: Encontro com o Outro sexo? Latusa, (21), 165-171.

Zucchi, M. (2016). Sexo na adolescência: As mesmas ou novas crises? Latusa, (21), 85-91.

\section{Endereço para correspondência}

Fernanda Guimarães Pougy

Email: fpougy@gmail.com

Angélica Bastos Grimberg

Email: abastosg@terra.com.br

Recebido em: 24/09/2016

Revisado em: 22/11/2017

Aceito em: 15/12/2017 